\title{
Bismuth Oxide Prepared by Sol-Gel Method: Variation of Physicochemical Characteristics and Photocatalytic Activity Due to Difference in Calcination Temperature
}

\author{
Yayuk Astuti ${ }^{\star}$ Brigita Maria Listyani, Linda Suyati, and Adi Darmawan \\ Department of Chemistry, Faculty of Science and Mathematics, Diponegoro University, \\ Jl. Prof. Soedharto SH, Tembalang, Semarang 50275, Indonesia
}

\section{* Corresponding author:}

email:yayuk.astuti@live.undip.ac.id

Received: January 4, 2020

Accepted: June 9, 2020

DOI: $10.22146 / \mathrm{ijc} .53144$

\begin{abstract}
Research on synthesis of bismuth oxide $\left(\mathrm{Bi}_{2} \mathrm{O}_{3}\right)$ using sol-gel method with varying calcination temperatures at 500,600 , and $700{ }^{\circ} \mathrm{C}$ has been done. This study aims to determine the effect of calcination temperature on the characteristics of the obtained products which encompasses crystal structure, surface morphology, band-gap energy, and photocatalytic activity for the decolorization of methyl orange dyes through its kinetic study. Bismuth oxide prepared by sol-gel method was undertaken by dissolving $\mathrm{Bi}\left(\mathrm{NO}_{3}\right)_{3} \cdot 5 \mathrm{H}_{2} \mathrm{O}$ and citric acid in $\mathrm{HNO}_{3}$. The mixture was stirred then heated at $100{ }^{\circ} \mathrm{C}$. The gel formed was dried in the oven and then calcined at 500, 600, and $700{ }^{\circ} \mathrm{C}$ for $5 \mathrm{~h}$. The obtained products were a pale yellow powder, indicating the formation of bismuth oxide. This is confirmed by the existence of $\mathrm{Bi}-\mathrm{O}$ and $\mathrm{Bi}-\mathrm{O}-\mathrm{Bi}$ functional groups through FTIR analysis. All three products possess the same mixed crystal structures of $\alpha-\mathrm{Bi}_{2} \mathrm{O}_{3}$ (monoclinic) and $\gamma_{-} \mathrm{Bi}_{2} \mathrm{O}_{3}$ (body center cubic), but their morphologies and band gap values are different. The higher the calcination temperature, the larger the particle size and the smaller the band gap value. The accumulative differences in characteristics appoint SG700 to have the highest photocatalytic activity compared to SG600 and SG500 as indicated by its percent degradation value and decolorization rate constant.
\end{abstract}

Keywords: bismuth oxide; sol-gel; calcination temperature; photocatalytic activity; photocatalyst

\section{- INTRODUCTION}

Bismuth oxide $\left(\mathrm{Bi}_{2} \mathrm{O}_{3}\right)$ is a semiconductor metal in the form of a yellow solid that has a melting point of around $825^{\circ} \mathrm{C}$ [1]. Bismuth oxide has potential as a solid oxide fuel cell [2] and photocatalyst [3-5] since it has a wide band gap energy of 2-3.96 eV [6]. In general, bismuth oxide has six types polymorphs comprising of $\alpha-\mathrm{Bi}_{2} \mathrm{O}_{3}$ (monoclinic), $\beta-\mathrm{Bi}_{2} \mathrm{O}_{3}$ (tetragonal), $\gamma-\mathrm{Bi}_{2} \mathrm{O}_{3}$ (body-centered cubic), $\varepsilon-\mathrm{Bi}_{2} \mathrm{O}_{3}$ (orthorhombic), $\delta-\mathrm{Bi}_{2} \mathrm{O}_{3}$ (face-centered cubic), and $\omega-\mathrm{Bi}_{2} \mathrm{O}_{3}$ (triclinic). The formation of $\alpha-\mathrm{Bi}_{2} \mathrm{O}_{3}$ is stable at low temperatures whereas $\delta-\mathrm{Bi}_{2} \mathrm{O}_{3}$ is stable at high temperatures; others have metastable crystal structures [7].

Bismuth oxide $\left(\mathrm{Bi}_{2} \mathrm{O}_{3}\right)$ can be synthesized by several methods, including precipitation [8] or deposition [9], solution combustion [10-12], hydrothermal [13], and solgel methods [1]. In this study the sol-gel (SG) method was applied with variations in calcination temperatures of 500, 600, and $700{ }^{\circ} \mathrm{C}$. Among these methods, the sol-gel method has several advantages, including high purity, high degree of homogeneity because the reagents are mixed at the molecular level, synthesis at low temperatures because certain materials can be carried out at room temperature [14], no reaction with residual compounds and loss of material because evaporation can be reduced [15]. The sol-gel method is one of the "wet methods", where changes occur from liquid precursors to sols and finally to a network of structure called 'gel' that will form a solid during calcination [16]. Calcination temperature has a significant effect on the crystallinity, structure and surface properties of the synthesized product because at the sol-gel method stage, heating plays an important role in the formation of 
solids in which heat applied to some substances lead to chemical reactions or chemical changes which further lead to formation of one or more substances with different properties [17-18].

Xiaohong et al. [19] has synthesized bismuth oxide in the form of films using different variations of annealing temperature composed of monoclinic and tetragonal crystalline phases. The result showed that the photocatalytic activity of bismuth oxide on Rhodamine B dye degradation was the highest at $550^{\circ} \mathrm{C}$ since it contained high tetragonal crystalline phase. Mallahi et al. [1] have synthesized bismuth oxide in the form of nanoparticles through the sol-gel method with calcination temperature variations of $200,500,800^{\circ} \mathrm{C}$ and studied changes in the surface morphology of the synthesized surface. At these temperature variations, the crystals have an irregular pseudospheric surface shape and when the calcination temperature was raised to $800{ }^{\circ} \mathrm{C}$, the particles acquired a lumpy shape. Exploration of the potential of bismuth oxide as a photocatalyst was not carried out in this study. In contrast to previous studies, this study was conducted to synthesize bismuth oxide through the sol-gel (SG) method with calcination temperature variations of 500,600, and $700{ }^{\circ} \mathrm{C}$ and a $1: 2$ ratio of bismuth nitrate pentahydrate to citric acid. Citric acid is a weak triprotic acid with three carboxylic acid functional groups, capable of forming various complexes with metal ions. It is an effective chelating agent. When aqueous metal salts (e.g. nitrates) are added with citric acid and then heated, a viscous solution or gel is formed [16]. This study also determined the product's physico-chemical characteristics such as the crystal structure, morphology, band gap values, and investigated their photocatalytic properties in degrading organic dyes. The findings of this research are expected to contribute to the science of the effect of calcination temperature within the sol-gel method on the physicochemical characteristics and performance of bismuth oxide as a photocatalyst in the degradation of organic dyes.

\section{- EXPERIMENTAL SECTION}

\section{Materials}

The materials used in this study were $\mathrm{Bi}\left(\mathrm{NO}_{3}\right)_{3} \cdot 5 \mathrm{H}_{2} \mathrm{O}$ from Sigma-Aldrich (white color powder and soluble in dilute nitric acid solution), nitric acid $\left(\mathrm{HNO}_{3}\right)$ 65\% from Merck (clear colorless liquid, strong acid), citric acid monohydrate from Merck (weak acid, colorless and odorless crystals with an acid taste), Polyethylene Glycol (PEG) 6000 from Merck (white color powder and odorless crystals), methyl orange (MO) from Merck (orange-yellow powder or crystalline scales), distilled water (purified water, applied as solvent, colorless and odorless liquid).

\section{Procedure}

\section{Bismuth oxide synthesis}

The synthesis of Bismuth oxide through the sol-gel method followed the method recommended by Mallahi et al. [1] with a slight modification. Synthesis of bismuth oxide by the sol-gel method was proceeded by preparing $4 \mathrm{~g}$ of $\mathrm{Bi}\left(\mathrm{NO}_{3}\right)_{3} \cdot 5 \mathrm{H}_{2} \mathrm{O}$ which was dissolved in a $50 \mathrm{~mL}$ nitric acid solution and mixed with citric acid solution with a molar ratio of 1:2. Subsequently, $1 \mathrm{~g}$ of PEG 6000 was added and the solution was heated to $90^{\circ} \mathrm{C}$ for $20 \mathrm{~h}$ whilst being stirred at a moderate speed of $667 \mathrm{rpm}$. The solution was allowed to stand in an aging process (ripening) for $12 \mathrm{~h}$ to form a gel. The formed gel was then dried in an oven at $100^{\circ} \mathrm{C}$ for $12 \mathrm{~h}$. The calcination process was later carried out for $5 \mathrm{~h}$ with variations in temperature at 500, 600 , and $700{ }^{\circ} \mathrm{C}$ (SG500, SG600, and SG700).

\section{Characterization of synthesized bismuth oxide}

Product characterizations were carried out using FTIR, XRD, SEM, and DRS-UV. Characterization using infrared spectroscopy was carried out using an ALPHA type FTIR BRUKER spectrometer with wavenumber in the range of $400-4000 \mathrm{~cm}^{-1}$ to determine the functional groups contained in the synthesized product. Meanwhile, characterization using XRD (XRD Bruker) was carried out by firing the sample with $\mathrm{X}$-rays of a $\mathrm{CuKa}$ source that has a wavelength of $1.54178 \AA$ and a voltage of $30.0 \mathrm{kV}$. The XRD patterns were collected at the diffraction angle range of $2 \theta=10-80^{\circ}$ with an angle step of $0.02^{\circ}$. The XRD patterns were then compared with the Joint Commission on Powder Diffraction Standards (JCPDS) data.

Morphological characterization of the samples was carried out using SEM (JEOL-JSM-6510LV) with an 
energy range of $0-20 \mathrm{keV}$, a voltage of $20.0 \mathrm{kV}$, and a calculating speed of 2729 cps. The UV-Vis spectra was collected using the UV 1700 Pharmaspec DRS-UV instrument with wavelength of $200-800 \mathrm{~nm}$ to obtain the $R$ values. The $R$ values were then processed by using the Kubelka Munk method to determine the band gap value.

\section{Photocatalytic activity test}

A total of $0.1 \mathrm{~g}$ of bismuth oxide sample (SG500) was put into $50 \mathrm{~mL}$ of $5 \mathrm{ppm}$ methyl orange solution and the solution was stirred at a medium speed of $667 \mathrm{rpm}$. The stirring process was carried out for $2 \mathrm{~h}$ for photocatalyst test without light, while photocatalyst test with light was carried out using UV-A (352 nm) with 15 watts of power and time variations of $60,90,120,150$, and $180 \mathrm{~min}$. After photocatalysis, the solution was filtered and the filtrate was then analyzed using UV-Vis spectroscopy at a wavelength of $463 \mathrm{~nm}$. This procedure was applied to products SG600 and SG700. A schematic of the photocatalysis reactor is shown in Fig. 1.

\section{- RESULTS AND DISCUSSION}

\section{Bismuth Oxide Synthesis}

The synthesis of bismuth oxide involved the use of sol-gel method with bismuth nitrate pentahydrate $\left(\mathrm{Bi}\left(\mathrm{NO}_{3}\right)_{3} \cdot 5 \mathrm{H}_{2} \mathrm{O}\right)$ as a precursor, citric acid as a complexing agent and $\mathrm{HNO}_{3}$ as a solvent. In addition, polyethylene glycol (PEG 6000) was also added as a dispersing agent that prevents agglomeration or clumping of products [20]. The sol-gel reaction initially occurred with the formation of a citrate-metal complex that reacted to form chelates with the addition polyethylene glycol assisted by stirring and heating at a temperature of around $90^{\circ} \mathrm{C}$. This would enable cross-linking to occur and form a gel through an esterification process [21]. The formed gel was dried in an oven at $100{ }^{\circ} \mathrm{C}$ for $12 \mathrm{~h}$ to remove remaining solvent in the synthesized product. The obtained result was a swollen yellowish brown xerogel. The xerogel was then calcined in a furnace to obtain yellow powder with different masses of 1.635 , 1.683, and $1.587 \mathrm{~g}$ for SG500, SG600 and SG700, respectively (see Fig. 2). The weight difference among the products is insignificant even though the degradation of elements derived from PEG 6000, citric acid and nitric acid indeed occurred due to the high calcination temperature. This can be identified by the absence of functional groups of those compounds observed in FTIR spectra as presented in Fig. 3. Moreover, the yellow color possessed by the three samples signified that bismuth oxide had formed [22].

The three products (SG500, SG600, SG700) were further analyzed using FTIR to identify the presence of vibration group of $\mathrm{Bi}-\mathrm{O}$ or $\mathrm{Bi}-\mathrm{O}-\mathrm{Bi}$ functional groups.

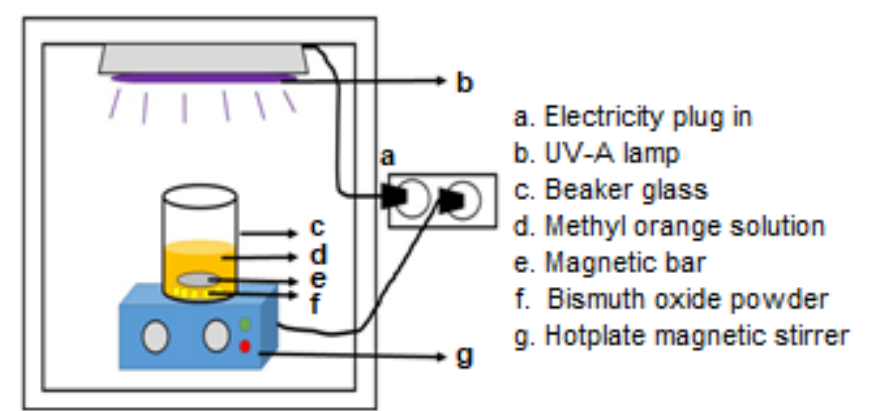

Fig 1. Scheme of a photocatalysis reactor used in the photocatalysis process

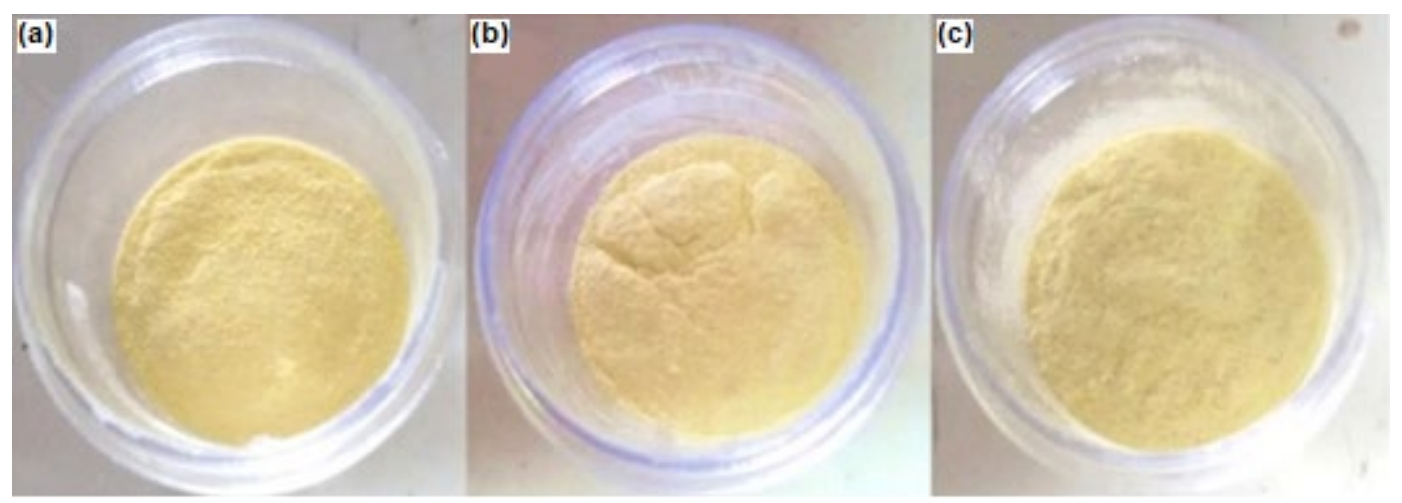

Fig 2. Powders of synthesized bismuth oxide: (a) SG500; (b) SG600; (c) SG700 


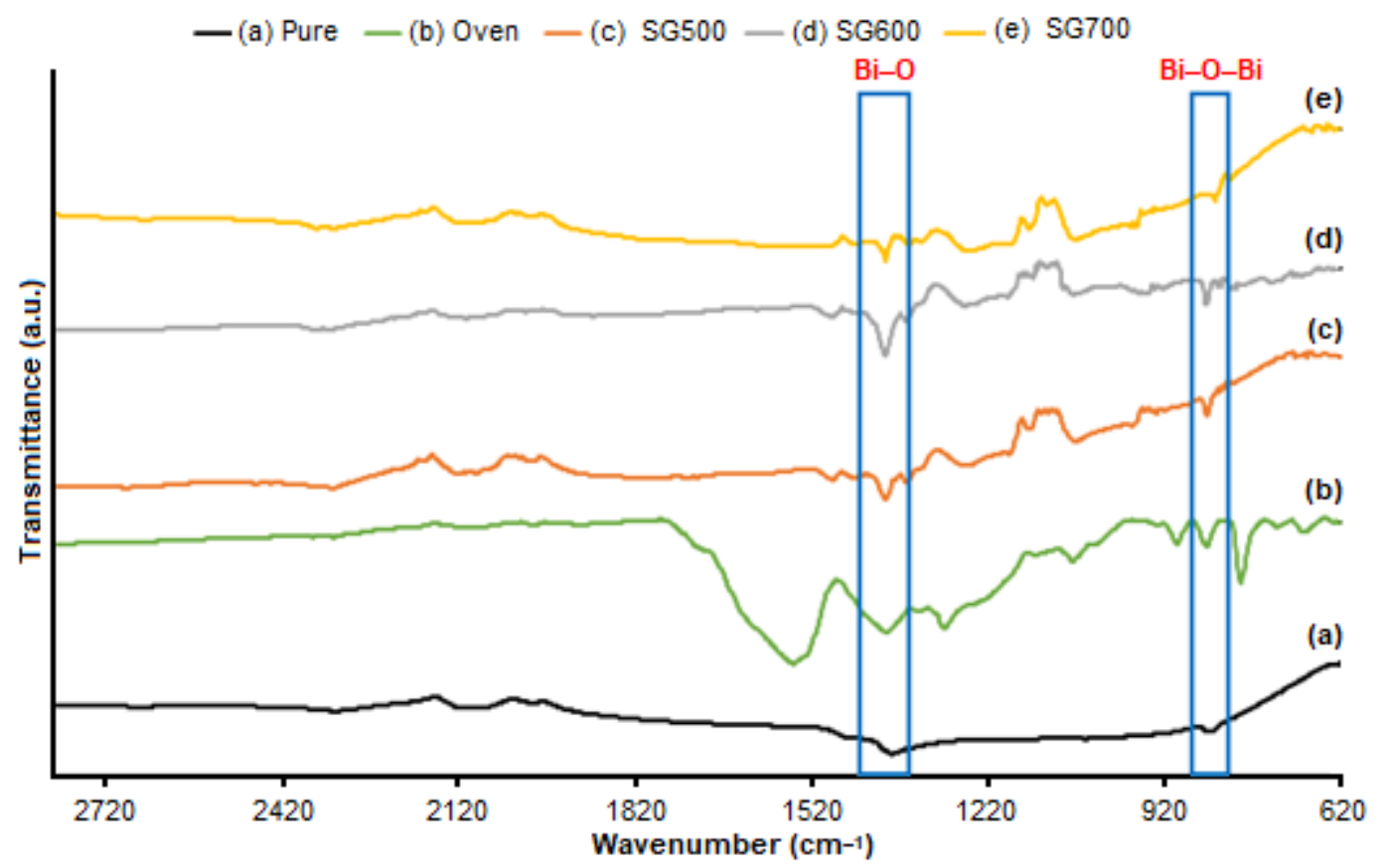

Fig 3. FTIR spectra of bismuth oxide: (a) pure [12]; (b) oven, (c) SG500; (d) SG600; (e) SG700

Fig. 3(c), (d), and (e) show the respective bismuth oxide FTIR spectra of SG500, SG600 and SG700. FTIR spectra show absorbances at around 848,850 , and $834 \mathrm{~cm}^{-1}$ indicating the symmetrical stretching of $\mathrm{Bi}-\mathrm{O}-\mathrm{Bi}$ bonds [23-25]. In addition, the wavenumber $1394 \mathrm{~cm}^{-1}$ points to the stretching vibration of the $\mathrm{Bi}-\mathrm{O}$ bond [25]. These spectra indicate that bismuth oxide has formed. These results are also confirmed by the pure bismuth FTIR spectrum in Fig. 3(a) showing similar absorption patterns at wavenumbers around 840 and $1384 \mathrm{~cm}^{-1}$ [12].

In addition, the content of the $\mathrm{Bi}-\mathrm{O}-\mathrm{Bi}$ functional groups in each product can be predicted through a comparison approach between the peak absorbance of $840 \mathrm{~cm}^{-1}$ attributed to vibration mode of $\mathrm{Bi}-\mathrm{O}-\mathrm{Bi}$ and $2100 \mathrm{~cm}^{-1}$ as control (constant wavenumber). Peak at $2100 \mathrm{~cm}^{-1}$ was applied as control since it was observed at every sample. Table 1 shows that bismuth oxide SG700 has the highest absorbance ratio value for the $\mathrm{Bi}-\mathrm{O}-\mathrm{Bi}$ group.
The high ratio of $\mathrm{Bi}-\mathrm{O}-\mathrm{Bi}$ on the $\mathrm{SG700}$ is due to the high calcination temperature applied followed by SG600 and SG500. Calcination temperature influences the formation of $\mathrm{Bi}_{2} \mathrm{O}_{3}$. As shown in Fig. 4, the $\mathrm{SG} 500$ shows rough $\mathrm{X}$ ray diffraction patterns indicating an imperfect crystal growth and as the temperature rises, the $\mathrm{X}$-ray diffraction pattern becomes smoother as seen in the SG600 and SG700. Therefore, increasing the calcination temperature improved the crystallinity of the product.This also occurred in the synthesis of bismuth oxides doped with Europium [26] and $\mathrm{Co}_{3} \mathrm{O}_{4}$ [27].

\section{Characteristics of Synthesized Bismuth Oxides Crystal structure}

The crystal structure of the synthesized bismuth oxide was identified using XRD. The XRD patterns were obtained and identified by comparing some of the highest peaks of the samples with peaks from the JCPDS

Table 1. Comparison of $\mathrm{Bi}-\mathrm{O}-\mathrm{Bi}$ bond and control absorbance ratios of the three products

\begin{tabular}{lccc}
\hline & Bi-O-Bi Group $\left(840 \mathrm{~cm}^{-1}\right)$ & Control Group $\left(2100 \mathrm{~cm}^{-1}\right)$ & $\mathrm{Bi}-\mathrm{O}-\mathrm{Bi} /$ Control Ratio \\
\hline Pure & 0.0828 & 0.0611 & 1.3554 \\
SG500 & 0.0535 & 0.1064 & 0.5032 \\
SG600 & 0.0314 & 0.0439 & 0.7162 \\
SG700 & 0.0653 & 0.0850 & 0.7684 \\
\hline
\end{tabular}




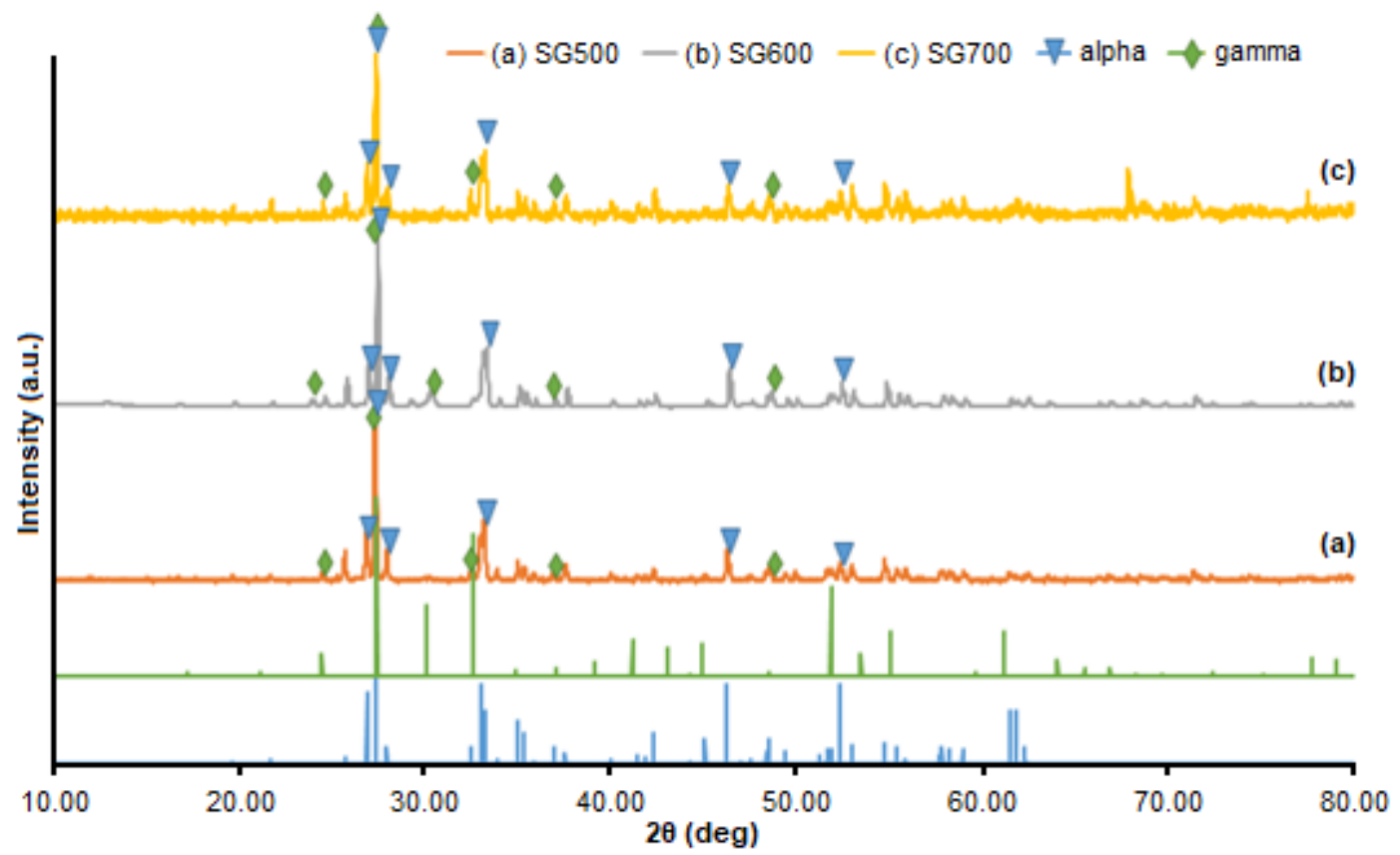

Fig 4. The XRD patterns of (a) SG500, (b) SG600, and (c) SG700 along with JCPDS database No. 41-1449 and 45-1344
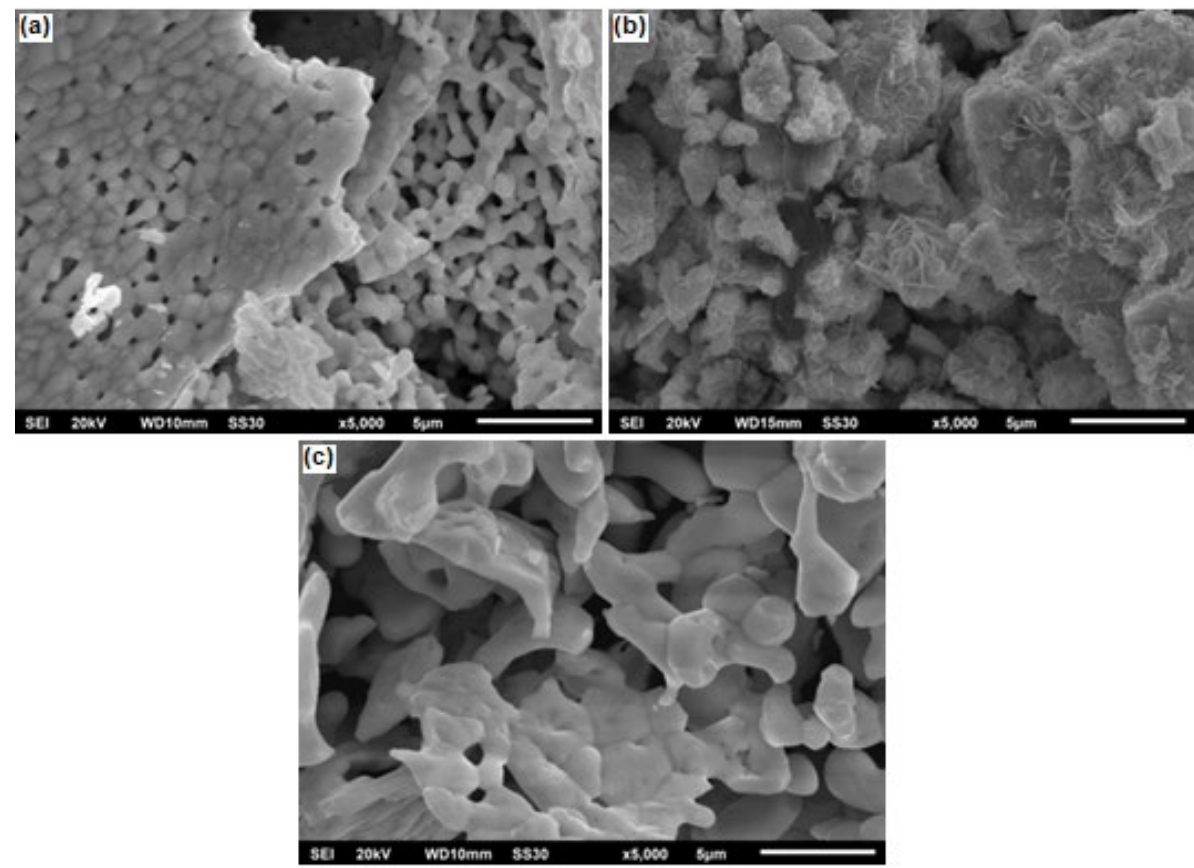

Fig 5. SEM images of bismuth oxide with 5000× magnification (a) SG500; (b) SG600; (c) SG700

database under the numbers $41-1449$ for $\alpha-\mathrm{Bi}_{2} \mathrm{O}_{3}$ and $45-$ 1344 for $\gamma-\mathrm{Bi}_{2} \mathrm{O}_{3}$. Fig. 4 shows that bismuth oxide SG500 has $\alpha-\mathrm{Bi}_{2} \mathrm{O}_{3}$ (monoclinic) crystal structure while SG600 and SG700 have the same mixed crystal structure of $\alpha$ $\mathrm{Bi}_{2} \mathrm{O}_{3}$ (monoclinic) and $\gamma-\mathrm{Bi}_{2} \mathrm{O}_{3}$ (body-centered cubic).

\section{Morphology}

Fig. 5(a) shows the crystal morphology of the SG500 bismuth oxide which has an irregular shape with a size of about 0.49-2.92 $\mu \mathrm{m}$. Fig. 5(b) shows irregular shape with whiskers-like form on the surface of the 
bismuth oxide SG600 crystal with uneven distribution of sizes, which are around 1.54-4.61 $\mu \mathrm{m}$. Fig. 5(c) shows the morphology of the SG700 bismuth oxide crystal surface which resembles a coral reef with an irregular shape and larger particle surface of about $0.71-6.30 \mu \mathrm{m}$ in which the surface of the particle is smoother than bismuth oxide SG600.

\section{Band-gap energy value}

Fig. 6 shows that the bismuth oxides of SG500, SG600 and SG700 have band gap energy values of 2.85, 2.80 , and $2.77 \mathrm{eV}$, respectively. Based on the band-gap energy value, it can be explained that a higher calcination temperature would result in the decrease of the band-gap energy. According to Cheng et al. [28], $\alpha-\mathrm{Bi}_{2} \mathrm{O}_{3}$ has a band-gap energy value of $2.81 \mathrm{eV}$. This is consistent with the XRD patterns in Fig. 4 that depict the presence of a mixture of $\alpha-\mathrm{Bi}_{2} \mathrm{O}_{3}$ and $\gamma-\mathrm{Bi}_{2} \mathrm{O}_{3}$ crystals. However, the DRS-UV analysis results show that the $\alpha-\mathrm{Bi}_{2} \mathrm{O}_{3}$ content was more dominant than $\gamma-\mathrm{Bi}_{2} \mathrm{O}_{3}$. All products contain $\alpha-\mathrm{Bi}_{2} \mathrm{O}_{3}$ since this polymorph is the most stable at room temperature. The band gap difference among the products
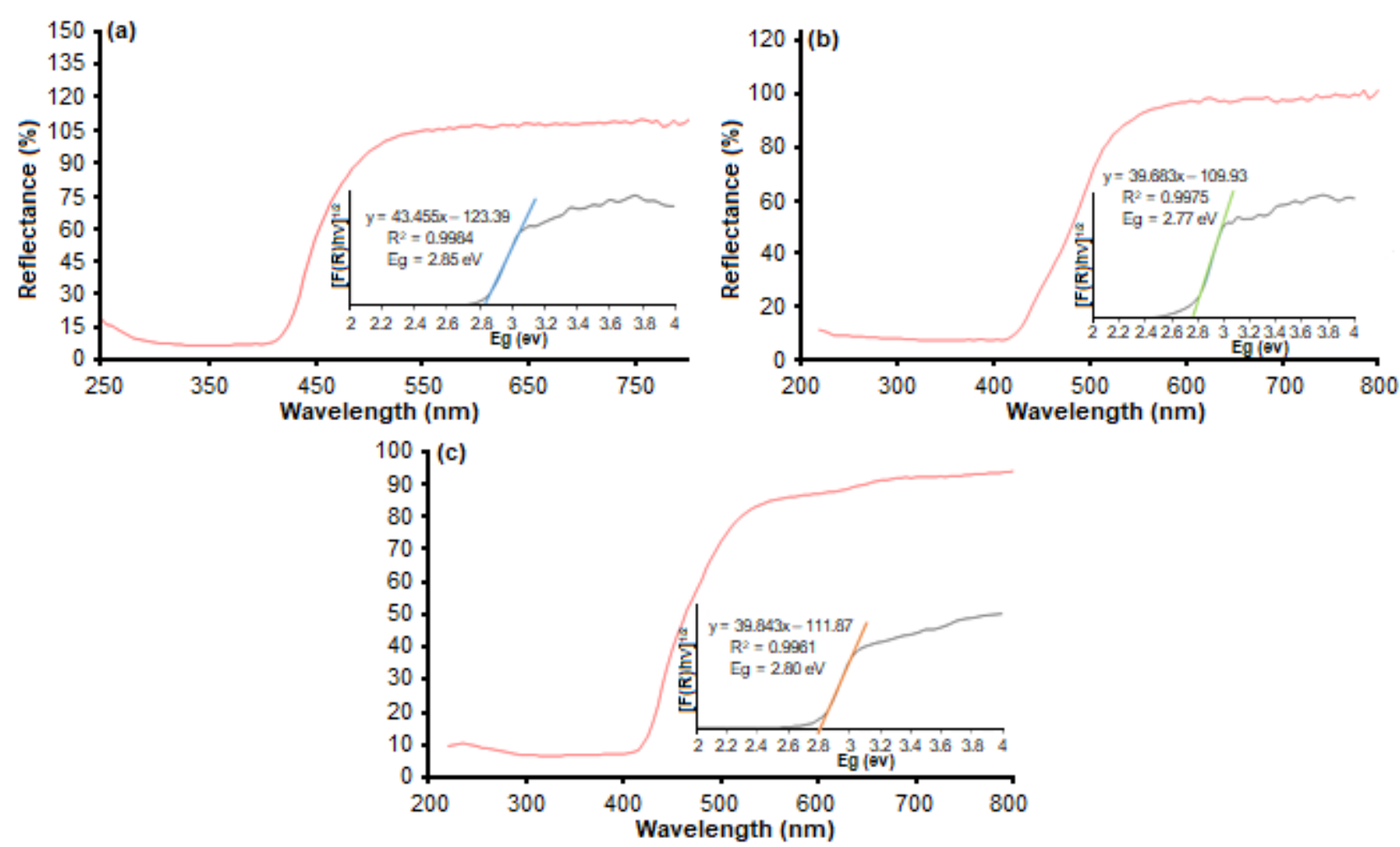

Fig 6. DR Spectra of (a) SG500, (b) SG600, (c) SG700 is due to the presence of other polymorphs. As reported by Hou et al. [29], the combined polymorph affects the band gap. The small band gap in the SG600 is possibly due to more $\gamma-\mathrm{Bi}_{2} \mathrm{O}_{3}$ content than other products which can be seen in the XRD patterns in Fig. 4(b) at the peak $2 \theta 30.124$. While, $\alpha-\mathrm{Bi}_{2} \mathrm{O}_{3}$ in the SG500 is dominant since the calcination temperature is temperature at which $\alpha-\mathrm{Bi}_{2} \mathrm{O}_{3}$ is formed.

\section{Photocatalytic Test}

The photocatalytic activity of the bismuth oxide SG500, SG600 and SG700 is shown in Fig. 7. Fig. 7(a) shows the UV-Vis spectra of methyl orange that has been decolorized by the three products over a 180 minute time span; whereas Fig. $7(\mathrm{~b})$ shows the percentage of decolorization of MO dyes by bismuth oxides SG500, SG600, and SG700. In Fig. 7(a) and 7(b), SG700 displays better photocatalytic activity compared to the other two products because it is able to reduce the highest concentration of methyl orange. This is because bismuth oxide SG700 has a higher Bismuth oxide content (see Fig. 3) and has the lowest band gap energy 

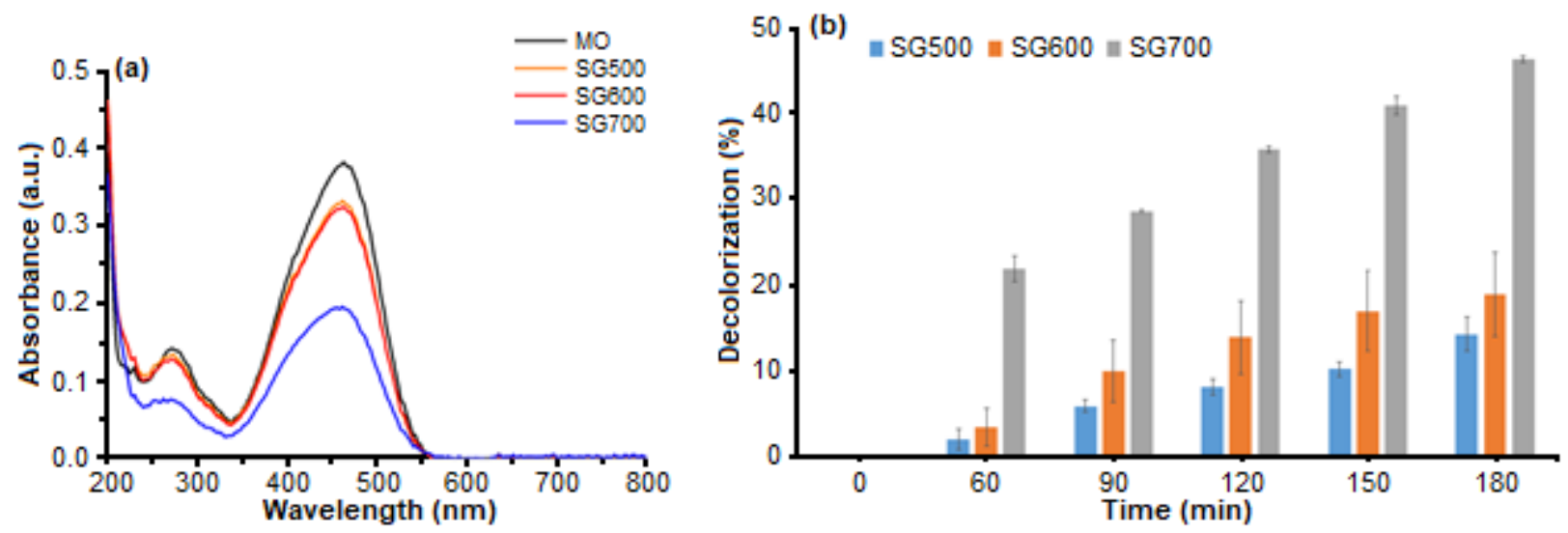

Fig 7. (a) UV-Vis Spectra of MO photocatalyzed for $180 \mathrm{~min}$; (b) Decolorization percentages of MO dye

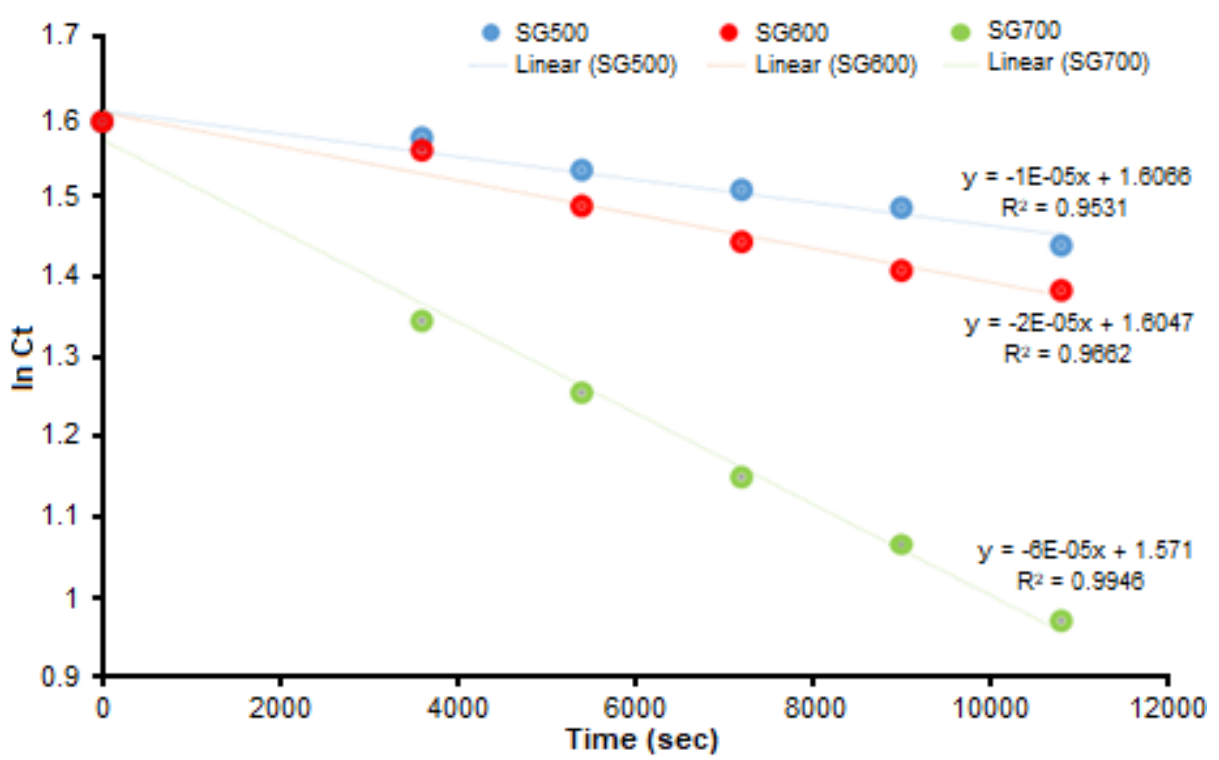

Fig 8. The first-order kinetic decolorization rate of methyl orange

value compared to the others as shown in Fig. 6. The smaller the band gap energy value of a compound or element, the easier the electrons are able to be excited resulting in a more impactful photocatalyst effect. In addition to band gap energy, bismuth oxide SG700 contains a mixture of $\alpha-\mathrm{Bi}_{2} \mathrm{O}_{3}$ and $\gamma-\mathrm{Bi}_{2} \mathrm{O}_{3}$ polymorphs (see Fig. 4). It has been mentioned previously that the combination of the two crystalline phase structures could increase the photocatalytic activity of bismuth oxide in the degradation of dyes [29].

To identify bismuth oxide is inactive as photocatalyst when the light is off, a photocatalytic test was also performed without the exposure of light for $2 \mathrm{~h}$. The test was also intended to discern the amount of methyl orange adsorbed by bismuth oxide. The percentage of methyl orange decolorization after $2 \mathrm{~h}$ without light in the presence of bismuth oxides SG500, SG600 and SG700 were $1.229,0.983$, and $0.368 \%$, respectively. These results indicate that $\mathrm{MO}$ dyes are not easily decolorized in a state without irradiation of light. The difference in adsorption activity for each sample is due to the morphological difference especially particle size as depicted by SEM images in Fig. 5 . The SG500 has the highest adsorption activity since having the smallest particle size range followed by SG600 and SG 700. The smaller the particle size the higher the surface area consequently the higher the adsorption activity.

The photocatalytic activity of synthesized bismuth oxide on MO dyes can be determined using decolorization rate calculations through chemical 
kinetics studies. Generally, the decolorization activity of dyes follows the kinetics of first-order reactions $[8,12,30$ 32] expressed by the formula:

$\mathrm{InCt}=\mathrm{InCo}-\mathrm{kt}$

with $\mathrm{k}=$ the reaction rate constant in the first order $\left(\mathrm{s}^{-1}\right)$, $\mathrm{C}_{0}=$ initial concentration of methyl orange solution (ppm), and $\mathrm{C}_{\mathrm{t}}=$ concentration of methyl orange solution $(\mathrm{ppm})$ at time t. This approach is substantiated by comparing the value of the correlation coefficient $\left(\mathrm{R}^{2}\right)$ between the methyl orange decolorization rate graphs and applying the integral equation of first and second order decolorization rates.

The values of the decolorization rates of methyl orange by bismuth oxides SG500, SG600, and SG700 (see Fig. 8) are $1.43 \times 10^{-5} \mathrm{~s}^{-1} ; 2.11 \times 10^{-5} \mathrm{~s}^{-1}$; and $5.69 \times 10^{-5} \mathrm{~s}^{-1}$, respectively. Based on the value of the decolorization rate constant, bismuth oxide SG700 has the highest reaction rate constant.

\section{- CONCLUSION}

The variation of calcination temperature in bismuth oxide synthesis affects the characteristics of the product obtained. In this study, the effects of calcination temperatures of 500,600 and $700{ }^{\circ} \mathrm{C}$ on bismuth oxide synthesis were investigated. Bismuth oxide calcined at $700{ }^{\circ} \mathrm{C}$ contained the highest $\mathrm{Bi}-\mathrm{O}-\mathrm{Bi}$ functional groups and a mixture of $\alpha-\mathrm{Bi}_{2} \mathrm{O}_{3}$ (monoclinic) and $\gamma-\mathrm{Bi}_{2} \mathrm{O}_{3}$ (bodycentered cubic) with a low band gap energy value. This characteristics led to bismuth oxide SG700 to have the highest photocatalytic activity even though the particle size is greater than others.

\section{- ACKNOWLEDGMENTS}

The authors would like to thank the Faculty of Natural Sciences and Mathematics and Diponegoro University for the financial support with grant number No. 1644a/UN7.5.8/PP/2017 and 831.1-05/UN7.P4.3/PP/ 2019 (scheme of Riset Publikasi Internasional (RPI)), respectively.

\section{- REFERENCES}

[1] Mallahi, M., Shokuhfar, A., Vaezi, M.R., Esmaeilirad, A., and Mazinani, V., 2014, Synthesis and characterization of bismuth oxide nanoparticles via sol-gel method, Am. J. Eng. Res., 3 (4), 162-165.

[2] Sammes, N.M., Tompsett, G.A., Näfe, H., and Aldinger, F., 1999, Bismuth based oxide electrolytes-Structure and ionic conductivity, $J$. Eur. Ceram. Soc., 19 (10), 1801-1826.

[3] Weidong, H., Wei, Q., Xiaohong, W., Xianbo, D., Long, C., and Zhaohua, J., 2007, The photocatalytic properties of bismuth oxide films prepared through the sol-gel method, Thin Solid Films, 515 (13), 5362-5365.

[4] Zhang, L., Ghimire, P., Phuriragpitikhon, J., Jiang, B., Gonçalves, A.A.S, and Jaroniec, M., 2018, Facile formation of metallic bismuth/bismuth oxide heterojunction on porous carbon with enhanced photocatalytic activity, J. Colloid Interface Sci., 513, 82-91.

[5] Reverberi, A.P., Varbanov, P.S., Vocciante, M., and Fabiano, B., 2018, Bismuth oxide-related photocatalysts in green nanotechnology: A critical analysis, Front. Chem. Sci. Eng., 12 (4), 878-892.

[6] Jiang, H.Y., Li, P., Liu, G., Ye, J., and Lin, J., 2015, Synthesis and photocatalytic properties of metastable $\beta-\mathrm{Bi}_{2} \mathrm{O}_{3}$ stabilized by surfacecoordination effects, J. Mater. Chem. A, 3 (9), 51195125 .

[7] Yilmaz, S., Turkoglu, O., Ari, M., and Belenli, I., 2011, Electrical conductivity of the ionic conductor tetragonal $\left(\mathrm{Bi}_{2} \mathrm{O}_{3}\right)_{1-\mathrm{x}}\left(\mathrm{Eu}_{2} \mathrm{O}_{3}\right)_{\mathrm{x}}$, Cerâmica, 57 (342), 185-192.

[8] Astuti, Y., Andianingrum, R., Arnelli, A., Haris, A., and Darmawan, A., 2020, The role of $\mathrm{H}_{2} \mathrm{C}_{2} \mathrm{O}_{4}$ and $\mathrm{Na}_{2} \mathrm{CO}_{3}$ as precipitating agents on the physichochemical properties and photocatalytic activity of bismuth oxide, Open Chem., 18 (1), 129137.

[9] Hernandez-Delgadillo, R., Velasco-Arias, D., Martinez-Sanmiguel, J.J., Diaz, D., Zumeta-Dube, I., Arevalo-Niño, K., and Cabral-Romero, C., 2013, Bismuth oxide aqueous colloidal nanoparticles inhibit Candida albicans growth and biofilm formation, Int. J. Nanomed., 8, 1645-1652. 
[10] La, J., Huang, Y., Luo, G., Lai, J., Liu, C., and Chu, G., 2013, Synthesis of bismuth oxide nanoparticles by solution combustion method, Part. Sci. Technol., 31 (3), 287-290.

[11] Astuti, Y., Fauziyah, A., Widiyandari, H., and Widodo, D.S., 2019, Studying impact of citric acidbismuth nitrate pentahydrate ratio on photocatalytic activity of bismuth oxide prepared by solution combustion method, Rasayan J. Chem., 12 (4), 22102217.

[12] Astuti, Y., Elesta, P.P., Widodo, D.S., Widiyandari, H., and Balgis, R., 2020, Hydrazine and urea fueledsolution combustion method for $\mathrm{Bi}_{2} \mathrm{O}_{3}$ synthesis: Characterization of physicochemical properties and photocatalytic activity, Bull. Chem. React. Eng. Catal., 15 (1), 104-111.

[13] Wu, C., Shen, L., Huang, Q., and Zhang, Y.C., 2011, Hydrothermal synthesis and characterization of $\mathrm{Bi}_{2} \mathrm{O}_{3}$ nanowires, Mater. Lett., 65 (7), 1134-1136.

[14] Amiri, A., 2016, Solid-phase microextraction-based sol-gel technique, TrAC, Trends Anal. Chem., 75, 57-74.

[15] Pinjari, D.V., Prasad, K., Gogate, P.R., Mhaske, S.T., and Pandit, A.B., 2015, Synthesis of titanium dioxide by ultrasound assisted sol-gel technique: effect of calcination and sonication time, Ultrason. Sonochem., 23,185-191.

[16] Danks, A.E., Hall, S.R., and Schnepp, Z., 2016, The evolution of 'sol-gel' chemistry as a technique for materials synthesis, Mater. Horiz., 3 (2), 91-112.

[17] Messel, H., 2014, Abridged Science for High School Students: The Nuclear Research Foundation School Certificate Integrated, Vol. II, Elsevier, London, UK.

[18] Miedema, A.R., Boom, R., and De Boer, F.R., 1975, On the heat of formation of solid alloys, J. Less Common. Met., 41 (2), 283-298.

[19] Xiaohong, W., Wei, Q., and Weidong, H., 2007, Thin bismuth oxide films prepared through the sol-gel method as photocatalyst, J. Mol. Catal. A: Chem., 261 (2), 167-171.

[20] Jiang, Z., and Wang, Y., 2015, Preparation of porous bismuth oxide by sol-gel method using citric acid, Material Science and Environmental Engineering:
Proceedings of the $3^{\text {rd }}$ Annual 2015 International Conference on Material Science and Environmental Engineering (ICMSEE2015), Wuhan, Hubei, China, 5-6 June 2015.

[21] Dimesso, L., 2016, "Pechini processes: An alternate approach of the sol-gel method, preparation, properties, and applications" in Handbook of SolGel Science and Technology, Springer, Cham, Switzerland, 1-22.

[22] Eastaugh, N., Walsh, V., Chaplin, T., and Siddall, R., 2008, Pigment Compendium: A Dictionary and Optical Microscopy of Historical Pigments, Routledge, London, UK.

[23] Selvapandiyan, M., and Sathiyaraj, K., 2019, Synthesis, preparation, structural, optical, morphological and elemental analysis of bismuth oxides nanoparticles, Silicon, 1-7.

[24] Bartonickova, E., Cihlar, J., and Castkova, K., 2007, Microwave-assisted synthesis of bismuth oxide, Process. Appl. Ceram., 1 (1-2), 29-33.

[25] Bandyopadhyay, S., and Dutta, A., 2017, Thermal, optical and dielectric properties of phase stabilized $\delta-\mathrm{Dy}-\mathrm{Bi}_{2} \mathrm{O}_{3}$ ionic conductors, J. Phys. Chem. Solids, 102, 12-20.

[26] Zhong, S., Zou, S., Peng, X., Ma, J., and Zhang, F., 2015, Effects of calcination temperature on preparation and properties of europium-doped bismuth oxide as visible light catalyst, J. Sol-Gel Sci. Technol., 74 (1), 220-226.

[27] Zhang, G., Hu, L., Wang, P., and Yuan, Y., 2017, The effect of calcination temperature on the performance of $\mathrm{Co}_{3} \mathrm{O}_{4}-\mathrm{Bi}_{2} \mathrm{O}_{3}$ as a heterogeneous catalyst of peroxymonosulfate, IOP Conf. Ser.: Earth Environ. Sci., 94, 012029.

[28] Cheng, H., Huang, B., Lu, J., Wang, Z., Xu, B., Qin, X., Zhang, X., and Dai, Y., 2010, Synergistic effect of crystal and electronic structures on the visiblelight-driven photocatalytic performances of $\mathrm{Bi}_{2} \mathrm{O}_{3}$ polymorphs, Phys. Chem. Chem. Phys., 12 (47), 15468-15475.

[29] Hou, J., Yang, C., Wang, Z., Zhou, W., Jiao, S., and Zhu, H., 2013, In situ synthesis of $\alpha-\beta$ phase heterojunction on $\mathrm{Bi}_{2} \mathrm{O}_{3}$ nanowires with 
exceptional visible-light photocatalytic performance, Appl. Catal., B, 142-143, 504-511.

[30] Liu, X., Deng, H., Yao, W., Jiang, Q., and Shen, J., 2015, Preparation and photocatalytic activity of Ydoped $\mathrm{Bi}_{2} \mathrm{O}_{3}$, J. Alloys Compd., 651, 135-142.

[31] Wang, Q., Hui, J., Yang, L., Huang, H., Cai, Y., Yin, S., and Ding, Y., 2014, Enhanced photocatalytic performance of $\mathrm{Bi}_{2} \mathrm{O}_{3} / \mathrm{H}-\mathrm{ZSM}-5$ composite for rhodamine B degradation under UV light irradiation, Appl. Surf. Sci., 289, 224-229.

[32] Astuti, Y., Amri, D., Widodo, D.S., Widiyandari, H., Balgis, R., and Ogi, T., 2020, Effect of fuels on the physicochemical properties and photocatalytic activity of bismuth oxide, synthesized using solution combustion method, Int. J. Technol., 11 (1), 26-36. 